\title{
SIGN LANGUAGE LEXICOGRAPHY IN THE EARLY 21ST CENTURY AND A RECENTLY PUBLISHED DICTIONARY OF SIGN LANGUAGE OF THE NETHERLANDS
}

Inge Zwitserlood: Radboud University Nijmegen, Dept. of Linguistics and Centre for Language Studies (i.zwitserlood@let.ru.nl)

T. Schermer, C. Koolhof (eds. in chief), S. Muller, J. Geuze, M. Vink (eds.). Van Dale Basiswoordenboek Nederlandse Gebarentaal (Basic Dictionary of Sign Language of the Netherlands). Van Dale. Utrecht and Antwerp. 2009. 560 pages. ISBN 978906648 0049 . $€ 39.95$. Annual subscription to the online version: $€ 20.00$

\begin{abstract}
Sign language lexicography has thus far been a relatively obscure area in the world of lexicography. Therefore, this article will contain background information on signed languages and the communities in which they are used, on the lexicography of sign languages, the situation in the Netherlands as well as a review of a sign language dictionary that has recently been published in the Netherlands.
\end{abstract}

\section{A brief background to signed languages}

Signed languages are natural languages that use the visual-gestural modality (instead of the oral-aural modality used by spoken languages), that develop and are used in communities with a sufficient number of deaf people. This is a rather broad definition, leaving open what 'sufficient' should mean. The fact is that this varies, depending on the community and its culture and attitude towards language. Until recently, it was assumed that signed languages were only used in what are called Deaf communities. ${ }^{1}$ Deaf communities are typically found in industrialized countries, where deaf people are considered disabled and are under a life-long pressure to integrate into the hearing world around 
them by using the spoken language of the community. Because this is very difficult for them and because people tend to seek company in which they can communicate effortlessly, they form special communities whenever possible. Although most members of a Deaf community have an auditory disability, this does not hold for all of them; members of a Deaf community are those who share a (Deaf) culture and (signed) language. However, it has been shown recently that there are also communities (often small, isolated villages) where a larger percentage of the people than usual are deaf and, due to regressive hereditary deafness, many (hearing) inhabitants have deaf family members, for which reason not only the deaf but also the hearing inhabitants sign (with varying signing skills), besides the use of a spoken language by the latter. Since the deaf are full members of these communities (in contrast to the deaf in industrialized countries), there is no need for separate Deaf communities (see Meir et al. in press).

Until relatively recently, signed languages have not been considered 'real' languages; it was generally assumed that they were either invented, or pantomimic in nature and understandable by all, and thus not complex abstract systems like spoken languages. Linguistic research into signed languages made a (slow) start in the mid-20th century (Tervoort 1953 on Sign Language of the Netherlands [NGT]; Stokoe 1960 on American Sign Language [ASL]) (See the Appendix for a list of abbreviations of the signed languages referred to in this paper.). Even then, skepticism about the results showing that they are real, natural languages remained until the early eighties. A gradual change of attitude towards signed languages came about only after various other studies concluded that the signed languages investigated indeed showed many of the features attributed to natural (spoken) languages, such as duality of patterning and phonological structure, morphological complexity, and (constraints on) syntactic structure. Signed language linguistics has extended through the years, although it still lags far behind the linguistics of spoken languages.

\section{Signed language dictionaries}

The life of a lexicographer is not an easy one. I dare say that the life of sign language lexicographers is even more difficult: they have to cope with a number of additional challenges to the ones that all lexicographers face. First, there is no orthography for signed languages. ${ }^{2}$ Although several sign notation systems have been developed, none of them is generally accepted, and most are considered too difficult for sign representation in dictionaries. Second, in almost all countries there are only a few signed sources from which the meaning(s) and grammatical characteristics of signs can be deduced and frequencies can be calculated. Third, signed languages are quite different from many spoken languages, particularly from Indo-European languages. Because the sign language may have a complex structure where the spoken language has a simple word 
and vice versa, it is often rather difficult to give a sign-for-word or word-for-sign translation. Finally, sign language lexicographers have to overcome the legacy of a tradition of (inadequate) compilation of sign language dictionaries set by non-professionals. These (interconnected) issues will be addressed below.

\section{I. Traditions in sign language dictionary compilation}

Even though signed languages have been looked upon as inferior communication systems for a long time, a variety of simple sign dictionaries have been compiled in the past. These were in general targeted at teachers and parents who needed to communicate in signs with their deaf pupils or deaf children when communication in spoken language failed. Most have been constructed by teachers, welfare workers and members of religious orders and in general they are merely bilingual wordlists, containing a basic set of written words from the spoken language, each word accompanied by a line drawing or a photograph of a person making the corresponding sign (Johnston 2003). Little (if any) further information on the sign was given, and it was not common at all to give more than one sign translation per word. These dictionaries were necessarily unidirectional, from the spoken to the signed language, and alphabetically or thematically (or both) ordered. Illustrations from an old dictionary of Danish Sign Language (DTS) (alphabetically ordered) are given in Figure 1.

When signed languages became more accepted as natural languages and the need to learn them increased, more dictionaries, containing more signs and more information about the signs, were needed. Also, specific groups of people demanded dictionaries with signs for the jargon they use, resulting in printed dictionaries in the domains of for instance animals and plants, sexual behavior, drug use, and mental health care. These dictionaries, even when compiled by professionals, usually had and still have the same format; although they are typically called 'The x sign language dictionary' (where x stands for a country), they are bilingual, and, with a few exceptions, unidirectional. Most dictionaries still match one word with one sign, and contain little further information about the signs.

\subsection{Sign representation and organization of dictionaries}

Dictionaries of spoken languages generally concern languages that have a written form, which is used to represent the words and other information in the dictionaries (e.g. definitions and explanations, context phrases). Spoken languages are basically one-dimensional in nature (speech sounds are pronounced one after another), which is reflected in the linear order of letters (or syllables) in the written form. ${ }^{3}$ Some dictionaries also contain information on lemma 
derne fores nedad, betegnende de 2 Sider af Graven. Dernast fores Handerne atter op i overste Stilling, idet den ene samtidig fores ind til Kroppen med Fladen udad, den anden foran denne med Ryggen udad, hvorpaa de atter begge sæenkes for at betegne de 2 andre Sider af Graven.

begynder, Begyndelse. $\left(I_{27}\right)$

Begge Pegefingre udstrakkes og holdes ved Siden af hinanden. Højre Haand fores saa ind mod Kroppen saaledes at hojre Pegefinger kommer til at glide opad venstre, der forbliver rolig.

beskytter, hjælper, forsvarer, Hjælp, ved, hos. $\left(I_{2 g}\right)$

Højre Haand holdes foran den venstre (Fingrene udstrakte) og bevæges op og ned (danner Skarm mod Faren).

bestemt, sand, Sandhed. $\left(I_{29}\right)$

Den aabne, kantstillede højre Haand slaas med et rask Slag ned mod den fladt udstrakte venstre Haand.

besøger, Besøg. $\left(\mathrm{I}_{30}\right)$

Den venstre Haand holdes fladt udstrakt med Ryggen opad. Den kantstillede højre Haand føres hen over Ryggen af den venstre.

betaler. $\left(I_{31}\right)$

Højre Haands Tommelfinger sattes mod Pegefingerens midterste Led (de andre Fingre lukkede) og Haanden anbringes paa den fladt udstrakte venstre Haandflade (som om man lagde Penge derpaa). Højre Haand fores derefter fremad $i$ en ret Linie.

Bjærg. $\left(\mathrm{I}_{39}\right)$

Den flade højre Haand med Fladen nedad og lidt spredte Fingre føres skraat op til højre i en svagt bølget Linie, betegnende Bjærgsiden. Øjet maa helst folge Bevagelsen.

\section{TAVLE I}

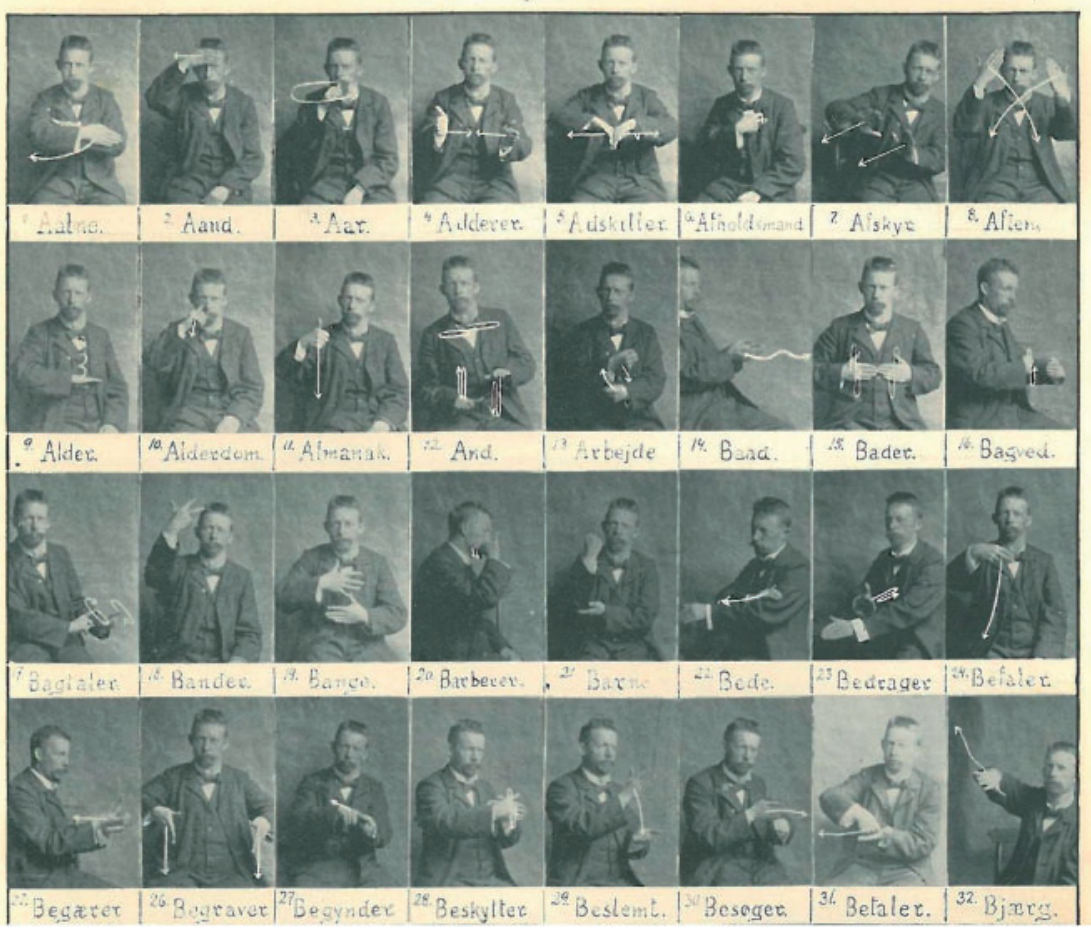

Figure 1: Parts from an early DTS dictionary (Jørgensen 1907). This figure appears in colour in the online version of the International Journal of Lexicography. 
pronunciation, mostly using IPA notation. Signed languages, in contrast, lack any form of orthography, and since in these languages speech sounds are not relevant, phonetic IPA notation is no solution for sign representation. The problem for sign notation is that a four-dimensional linguistic signal (signs use three-dimensional space and have sequential [temporal] structure) is difficult to represent in a static (one- or two-dimensional) representation. This issue is tackled in different ways by dictionary compilers, the most common one being the use of pictures or photo stills of a person making a sign. Sign notation systems are used in some dictionaries, but generally complementary to an image of the sign. More recently the problem is circumvented by the possibility of movie representation in electronic dictionaries. Each of these has its impact on the organization of the dictionary.

2.2.I Line drawings and stills. Most dictionaries, printed ones in particular, use line drawings or photographs to represent the signs. These were the only representation possibilities in the past, and the images are quite understandable even for the naive dictionary user, although the activity within the sign is obviously not visible in a still image. The activity is usually represented by arrows and other symbols that are added to the image (as in Figure 2), or by a sequence of images, as illustrated in Figure 3.

Representations with added activity symbols are still not very detailed, especially with respect to the non-manual part of the sign (the next section will

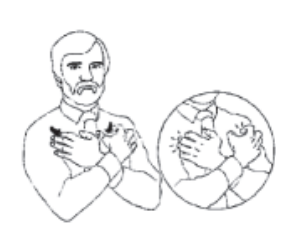

Bear (1) $n$ a large, heavy mammal with thick, rough fur: a grizzly bear.

\section{[Action of a bear scratching itself]}

With the arms crossed at the wrist on the chest, scratch the fingers of both curved hands up and down near each shoulder with a repeated movement.

Figure 2: Entry in a (printed) ASL dictionary (Costello 1998. Copyright (C) 1998; reprinted by permission of Random House).

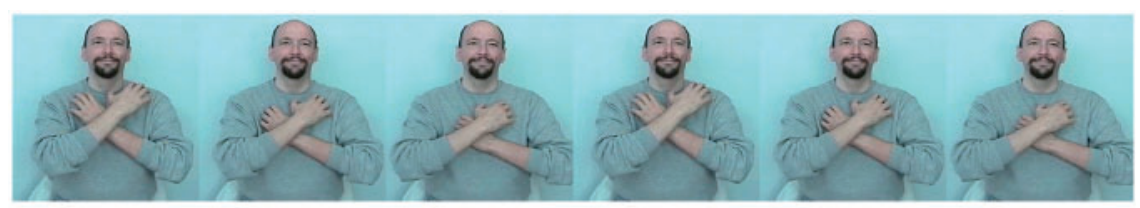

\section{Bear}

Figure 3: Entry in an online ASL dictionary (Vicars 1997). This figure appears in colour in the online version of the International Journal of Lexicography. 
discuss sign parts in some detail). On the other hand, representations such as the one in Figure 3 take an extraordinary amount of space and still are not easy in use. Extra information on pronunciation has been added in some dictionaries to remedy this (as in Figures 1 and 2). This adds, however, to another problem, viz. the space issue. The fact that images take much space makes it virtually impossible to provide information on lemmas in the signed language (thus, using images). For this reason, no printed bilingual dictionary from a spoken to a signed language exists that provides information on the lemmas in sign, let alone a monolingual sign language dictionary. Even bilingual dictionaries with a limited set of, say, a thousand lemmas are quite voluminous. As a result, most sign language dictionaries contain rather few entries compared to dictionaries of spoken languages, and additional information about the signs is provided in the spoken language.

A final disadvantage of sign images is that they are holistic units and as such, difficult to search or order, in contrast to the alphabetic (or syllabic) ordering of spoken language dictionaries. Only a few bilingual dictionaries contain images of signs and have an ordering based on sign structure. An example is the Preliminary Signing Dictionary of Australian Sign Language (Johnston 1987), that (besides an alphabetically ordered English-to-Auslan part) contains an Auslan-to-English part in which signs are ordered according to the values of the sign parameters (see the next section). Such efforts have not been taken for most printed dictionaries, however. In general they still tend to be bilingual, unidirectional, and alphabetically ordered on the basis of words of the spoken language.

2.2.2 Sign notation systems. Phonological research on signed languages, following Stokoe's (1960) original work, has shown that signs are built up from small, meaning-distinguishing units, just like words of spoken languages. The sign parameters are roughly:

(i) particular shapes of the hand(s);

(ii) activities of the hand(s) (e.g. movement of the hand(s) through space and opening or closing of the hand);

(iii) particular hand orientations;

(iv) places where the signs are made: on, near, or in front of the body; and

(v) various non-manual components, such as facial expressions and mouth patterns.

In contrast to the linearity of the spoken signal, the visual-gestural modality allows more simultaneous pronunciation of sign parameters: e.g. a handshape, orientation, and movement can be expressed at the same time at the same location. Still, signs also have sequential structure: there may be a movement 


\begin{tabular}{|c|c|}
\hline $\begin{array}{l}\text { Stokoe notation system } \\
\text { (Stokoe et al. 1965) }\end{array}$ & [ ] $\sqrt{ } C^{\dagger} \sqrt{ } C_{x}^{v-}$ \\
\hline HamNoSys & 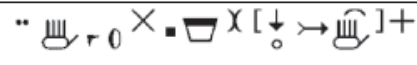 \\
\hline $\begin{array}{l}\text { SignWriting } \\
\text { (DAC 2010) }\end{array}$ & 茯落 \\
\hline
\end{tabular}

Figure 4: Representation of an ASL sign in three notation systems.

from one location to another, or a change in the shape or the orientation of the hand.

Several notation systems based on the shape of signs have been developed in the past decades. ${ }^{4}$ The most important of these systems are:

(i) the phonologically based Stokoe notation system (Stokoe et al. 1965);

(ii) the phonetic system HamNoSys (Prillwitz et al. 1989); and

(iii) a system that is meant to function as an orthography for signed languages: SignWriting (www.signwriting.org).

Each of these systems has sets of symbols for the different values for the sign parameters, and these symbols combine to represent the sign form. The systems are briefly illustrated in Figure 4, by their respective representations of the ASL sign shown in Figures 2 and 3.

Where the Stokoe and HamNoSys notations are mostly linearly ordered and rather abstract, the SignWriting representation is more holistic and the signs are easier to recognize. The symbols of the systems are explained in Figure 5.

At first sight, the SignWriting notation of our example seems much simpler than the other two notations. This is somewhat misleading, because some information that is made explicit in the other two systems, specifically HamNoSys, is implicit in the SignWriting representation. In the latter, information about the orientation of the hand is always present in the handshape symbol. For instance, w indicates that the hand palm is towards the signer; w and stand for palm to the side and palm away from the signer, respectively; 学 also indicates that the hand is parallel to the signer's body, whereas 光 is used to indicate that the hand is parallel to the floor. Similar use of shading is used in the movement symbols to indicate direction of movement (not present in the example used here). As a result of the combination of handshape and orientation in the handshape symbols, and movement or direction in the movement symbols, SignWriting has a much larger set of symbols than the other two systems. 


\begin{tabular}{|l|l|}
\hline \multicolumn{2}{|l|}{ Stokoe notation system } \\
\hline[] & hands are at or near torso \\
\hline$\sqrt{|l|}$ & forearm \\
\hline C & curved fingers \\
\hline$\uparrow$ & arms crossing \\
\hline$V$ & downward movement \\
\hline$\cdot$ & one repetition \\
\hline$x$ & articulators touch \\
\hline
\end{tabular}

\begin{tabular}{|l|l|}
\hline \multicolumn{2}{|l|}{ HamNoSys } \\
\hline $\boldsymbol{\ddots}$ & $\begin{array}{l}\text { configuration, and action of the left } \\
\text { hand mirrors that of the right hand }\end{array}$ \\
\hline ש & $\begin{array}{l}\text { fingers and thumb extended and } \\
\text { straight }\end{array}$ \\
\hline $\boldsymbol{D}$ & $\begin{array}{l}\text { fingers (of the right hand) pointing left } \\
\text { upwards }\end{array}$ \\
\hline$\times$ & palm (of the right hand) to the left \\
\hline$-\square$ & (right hand) at left side of the shoulders \\
\hline$X$ & contact with body part \\
\hline$\downarrow$ & downward movement \\
\hline$\circ$ & small movement \\
\hline$\succ$ & change in handshape (or orientation) \\
\hline$\frown$ & curved (finger or fingers) \\
\hline+ & one repetition \\
\hline
\end{tabular}

Figure 5: Explanation of the Stokoe and HamNoSys notation symbols.

Where the SignWriting notation forms rather holistic representations (although formed through combinations of symbols), the Stokoe and HamNoSys notations are (to some extent) linearly ordered. The more simultaneous nature of the sign structure allows different orderings of the symbols in each system (e.g. hand configuration comes first in HamNoSys followed by place of articulation, where the Stokoe system represents the place of articulation in the sign before the hand configuration). Thus, the ordering is a result of the choice of the developers. Still, due to the linear ordering of the symbols, Stokoe notation and HamNoSys facilitate the ordering of sign lemmas in a (printed) dictionary. However, so far there is only one dictionary that relies solely on the ordering of the lemmas by their notation and does not use images of signs at all (Stokoe et al. 1965). The entry for the sign in our example in this dictionary is as shown in Figure 6.

The Dictionary of British Sign Language (Brien 1992) also uses (an adapted version of) the Stokoe system to describe the lemmas, but although 


\section{[]$J C^{*} \lambda C_{x}^{*}$}

(imitative of bear hug; arms crossed on chest, dez claw downward) $\mathrm{N}$ bear.

Figure 6: Entry of the sign for 'bear' (Stokoe et al. 1965: 192).
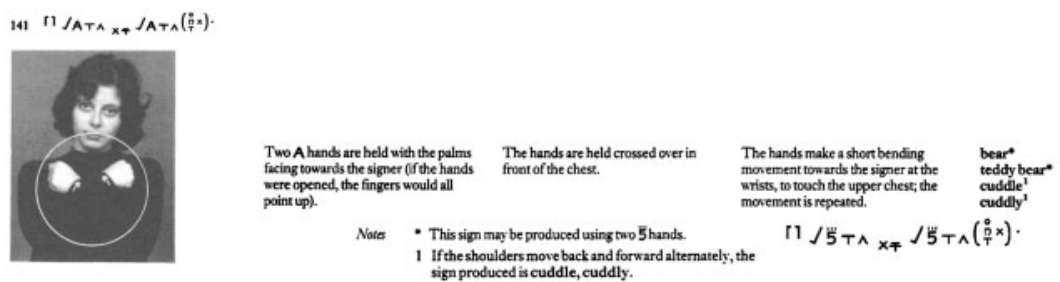

141

Figure 7: Entry of the sign for 'bear' (BSL) (Brien 1992: 182-183. Copyright (C) 1992. Reprinted with kind permission of the author.).

the signs are ordered according to parameter values, the ordering does not follow the linear ordering in the lemma notation: the signs are globally ordered according to handshape $>$ location $>$ orientation $>$ movement (and the specific values of these parameters). This dictionary also provides photographs of the signs, which are augmented with arrows and other symbols indicating the activity in the sign. The entry for the BSL sign for 'bear' is illustrated in Figure 7. (Note that ASL and BSL have different signs for 'bear'.)

2.2.3 Representation by videos. A solution to the representation problems is offered by the development of electronic sign language dictionaries, which has been made possible (and affordable) by advances in video processing and computer technology. Such dictionaries can provide digital movies of the signs that much better represent the signs' activities (including the non-manual parts, such as mouth movements), even though they do not (yet) allow for the representation of the use of three-dimensional space. Dictionaries on CD-ROM and DVD usually offer bidirectional search options. This is also possible in some on-line dictionaries, such as the Flemish-Flemish Sign Language (VGT) dictionary (Van Herreweeghe et al. 2004) and the quite recently published dictionaries of Swedish Sign Language (SSL; Institutionen för Lingvistik 2009), Danish Sign Language (DTS; Center for Tegnsprog 2008), and Finnish Sign Language (SVK; Kuurojen Liittory 2003). When searching signs in the VGT dictionary, the user is offered a list of 107 (phonetic) SignWriting handshape symbols for the hand(s) and four symbols for locations where the sign is made (head, torso, arms and legs). Choice of a location offers an additional search option of ways in which the hand(s) touch a body part (e.g. rubbing or grabbing). The results are shown in a list (unordered), and each 


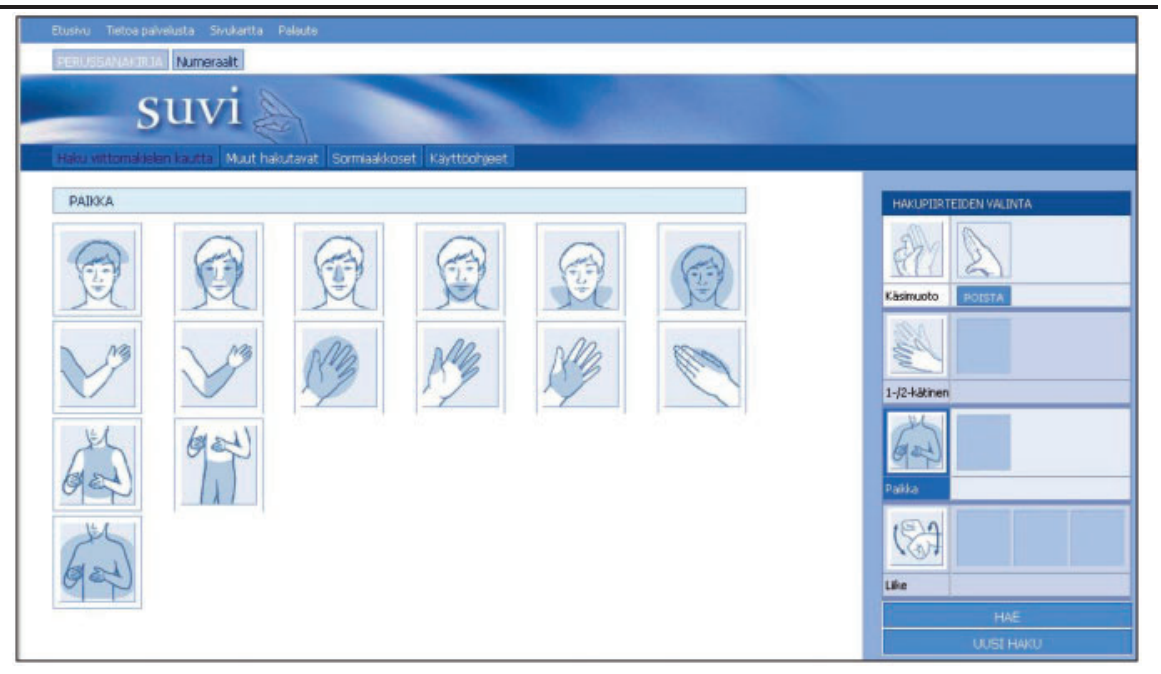

Figure 8: Location search options in the online SVK dictionary. This figure appears in colour in the online version of the International Journal of Lexicography.

hit can be clicked to show a clip of the sign as well as its full SignWriting notation.

The SSL, DTS and SVK dictionaries also offer handshape and location (and combinations) as major search options; however, the selection criteria are offered in a more user-friendly, graphic user interface, showing drawings of the hands and locations on and near the body. The selection possibilities for place of articulation in the SVK dictionary are illustrated in Figure 8. ${ }^{5}$

The SVK dictionary also offers the possibility to include the activities within a sign (e.g. movement, change in handshape, and change in orientation) in a search. The user can even search signs on the basis of mouth patterns. This can be done by selecting an item from a drop-down list of written mouth patterns, or by selecting one out of a list of photographs of faces with particular mouth patterns. The search results are shown in a list of photographs with translations in Finnish. More detailed information on a sign, including pronunciation and example sentences (both by movies) can be obtained by clicking the entry.

Searching signs in the DTS online dictionary can be done by (combinations of) handshape, location, and topic. ${ }^{6}$ Within the handshape category, it is possible to do a detailed or less detailed search, viz. the user can indicate that the sign has a handshape with an extended finger (general), or choose a particular phonetic variant of this handshape (e.g. with straight or bent extended finger, or with variant thumb position). This is illustrated in Figure 9 where the circled handshape has a set of four variants (indicated by a dotted oval); these shapes can be individually selected or combined in a search. This is an 


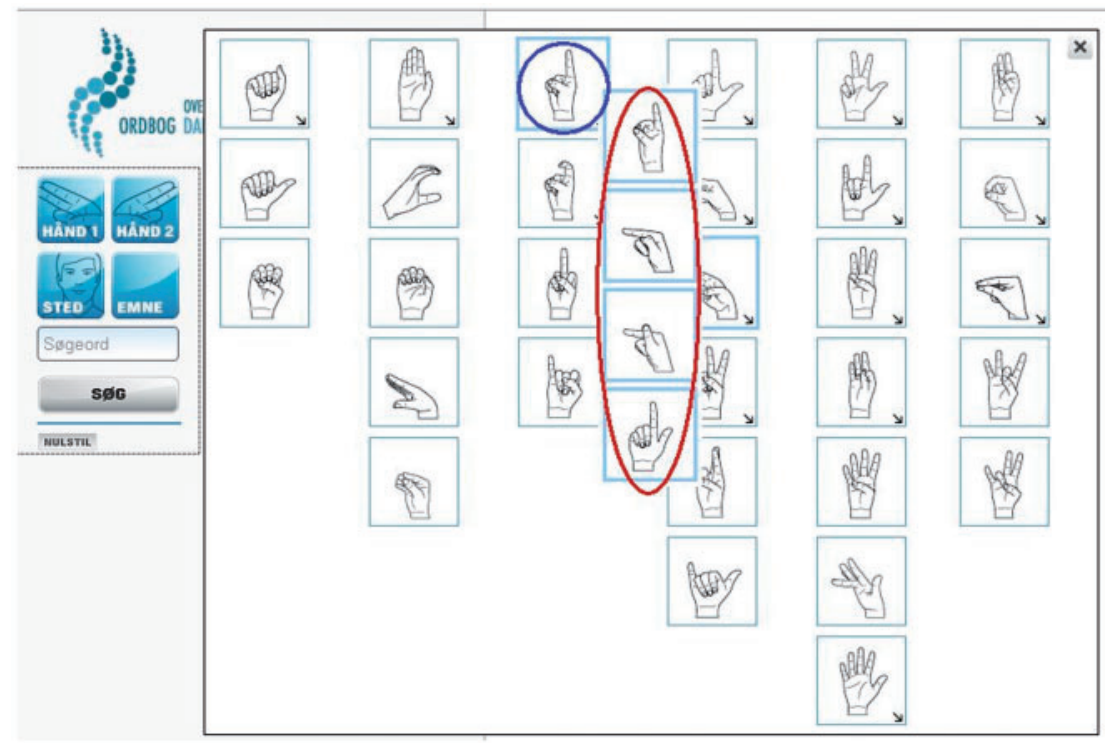

Figure 9: Handshape selection in a search in the DTS dictionary. This figure appears in colour in the online version of the International Journal of Lexicography.

advantage over dictionaries that only have the possibility of selecting a specific variant, and saves the user from having to perform searches with each variant.

A sign search in this dictionary results in a list of hits consisting of a still from the sign movie, a gloss, ${ }^{7}$ and the Danish translation(s). The hits can be ordered again according to handshape or location. Clicking an entry opens a new window that contains a range of information: besides repetition of the search options, there is a movie of the sign, there are Danish translations, glosses of DTS synonyms of the sign (that can be clicked to show the signs), and example sentences in DTS, with translations in Danish. The example sentences are given in glosses, so that each gloss can be clicked to show the movie for the sign it represents. To view the whole DTS sentence, one can click the 'play' symbol before the sentence. Below the movie there is a list of glosses of which the entry is a part, with translations in Danish, and again, the possibility to view the movies of each gloss. This information is shown in Figure 10.

Searching signs on the basis of sign parameter values is thus much easier in an electronic dictionary than in a printed one. The dictionary compilers still have to link the parameter values to the sign movies, but there is no ordering issue. The users of such a dictionary have to abstract away from the sign as a whole in order to be able to use the sign parameters in a search, but the presentation of such values can be done in a clear, user friendly way. And, most importantly, the representation of the signs is much clearer than in any 


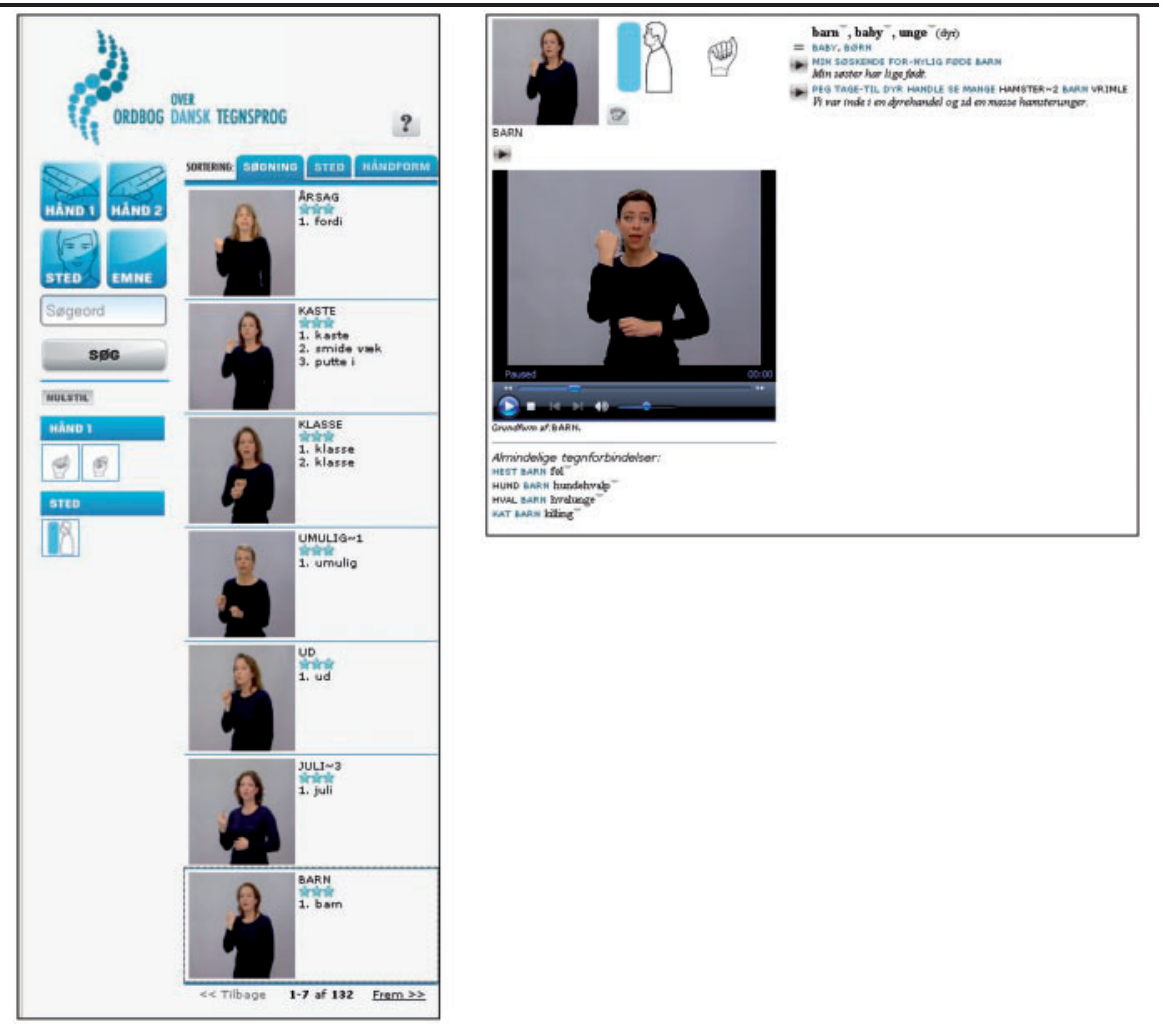

Figure 10: Search results in the DTS dictionary. This figure appears in colour in the online version of the International Journal of Lexicography.

printed dictionary, since a movie can be viewed (as well as a two-dimensional image).

Compiling such elaborate dictionaries is hard work. For that reason, there are only a few of them to date (although the number is growing), and many online sign language dictionaries are still unidirectional, giving only signed translations of words from a spoken language in a one-to-one relation (e.g. the American Sign Language Browser) ${ }^{8}$ and without additional information on the entry in the signed language. Also, electronic dictionaries still have rather small sets of entries, between 2,000 and 5,000.

\subsection{Sources}

As stated earlier, there are only few data sources of signed languages. Obviously, there are no written sources such as books, newspapers, or magazines. There are a few countries that have television broadcasts in the national signed language (e.g. the program 'See Hear!' in Great-Britain), but in most countries there are none. Recently, various kinds of movies in which signed 
language is used have begun to be published on the internet (e.g. isolated movies uploaded on You Tube by individuals, but also programs, such as internet news broadcasts), and some of these may be used as sources in the future. ${ }^{9}$ How, then, have the signs for sign language dictionaries been selected and collected until now?

In the earlier stages of sign language dictionary making, the function of the dictionaries was to provide (hearing) teachers and parents with signs for particular words, so that they could communicate about everyday objects and activities with their deaf pupils or children. Generally, lists of words that these people might need would be compiled and deaf signers were asked what sign they would use for each of the words. Based on the responses, word-sign pairs would be entered in the dictionary. Such sign elicitation procedures facilitate the production of a representation of a sign (a drawing or photograph), because the signers will do their utmost to sign clearly. However, there are many dangers attached to this procedure. The risk of suggesting to the user that there is a one-to-one relationship between words and signs has already been mentioned. Also, there is a real danger that in this way signs are elicited that are not actually in use (as such) in the sign language community. That is, there may not be an existing sign (yet), or the language may use a different strategy (e.g. a phrase or a clause) rather than a single sign to express a particular concept. Although the Deaf people involved in the procedure may produce a particular sign or sign combination that best matches the word for which a sign was requested, this sign (or sign combination) may not be the way in which the requested concept is actually expressed in the signed language. (This is a central problem of bilingual dictionary compilation and not restricted to signed language dictionaries.) Also, because of the long-term dominance of spoken languages, the informants may be influenced by the spoken language.

Despite these risks, the procedure of eliciting signs using words from a spoken language is still commonly used. Recent, ongoing and future digital sign language corpora (e.g. Johnston 2009, Crasborn and Zwitserlood 2008, and many to follow), combined with online resources (which are less restricted with respect to topicality and register than corpora), will support sign language lexicography considerably in providing large (elicited and semi-spontaneous) data sets, involving many language users of different areas and ages. Most importantly, in such sources signs occur in contexts, allowing deduction of the (subtle) meanings and functions of the signs that are necessary for the more sophisticated dictionaries that are needed nowadays.

\subsection{Sign complexity}

A final issue concerns the fact that signed languages are usually quite different in structure from the spoken language that is used in the same country or area. Where a spoken language may use nouns and verbs to refer to objects and 


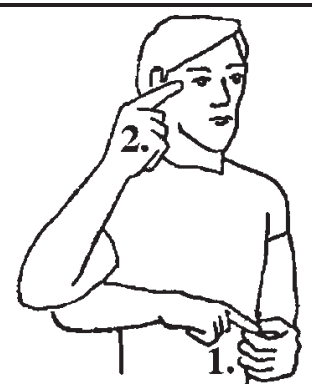

Figure 11: A complex Auslan sign (Johnston and Schembri 1999: 124. Copyright (C) 1999. Reprinted with kind permission of John Benjamins Publishing Company, Amsterdam and Philadelphia).

events, signed languages may use complex verbal or syntactic structures to do so. Thus, it is often rather difficult to give a translation in sign for a word from a spoken language and vice versa (Brien and Turner 1994). For instance, the Auslan sign in Figure 11 would be best translated as 'a finger or small implement dipped into a container and then wiped on the face' (Johnston and Schembri 1999: 124).

In many signed languages, sign parameter values coincide with morphemes, viz. morphemes can be expressed by handshapes (e.g. can mean 'long and thin entity'), but also by movements, places of articulation and other parameters. Signs are productively formed by combinations of such morphemes, and the decision whether or not to include the signs that result from productive sign formation rules in a dictionary is difficult to make (Brien and Brennan 1994, Johnston and Schembri 1999). A possibility would be to list the morphemes, were it not for the difficulty of representing some of the morphemes, for instance a movement without also representing a hand.

Finally, the morphological complexity of many signs is often not recognized or even denied, and thus not indicated or represented in dictionaries. There are various reasons for this, an important one resulting from the difficulty of sign representation. Sign language research (including lexicography) has a tradition of using glosses, to easily represent signs. Although the use of glosses is common in linguistics, sign language glosses differ from glosses used in the spoken language literature in that common glossing only labels (lexical and grammatical) information about the words and morphemes that are represented in the original orthography (or IPA), while sign language glosses, in the absence of the original utterance, represent the signs, and to represent grammatical information, extra codes and representations are used. ${ }^{10}$ Since a gloss often consists of a monomorphemic word or a word with a different morphological structure than the sign, the actual structure of the sign is usually disregarded. Thus, the Auslan sign in Figure 11 may be glossed as MASCARA, and consequently mistakenly considered a monomorphemic sign. ${ }^{11}$ Connected 
with this is the problem that signs are often taken to belong to the same word class as the gloss, while this is not necessarily the case (see Slobin 2008 for an overview of the problems resulting from the use of glosses). With a few exceptions (e.g. Brien 1992), dictionary compilers have seldom faced these challenges to date. Again, a different approach than the traditional one is needed in the future, using real sign language sources instead of sign elicitations, through which the different meanings and interpretations of the signs can be stated as well as other information can be found.

\section{Sign Language of the Netherlands (NGT) and its users}

Before we discuss the NGT dictionary, let us first look at the situation in which it was developed. It is estimated that there are 20,000 users of Sign Language of the Netherlands (NGT), only a quarter of whom are estimated to use it as a first language. These are mostly people who are born deaf or have become deaf early in life. NGT is a second (or third) language for approximately 15,000 people in the Netherlands. This group mainly consists of hearing family members of deaf people (particularly parents of deaf children) and hearing people involved in deaf education and welfare. Besides these, there are people who have learned NGT at a later age because they have become deaf, are deaf people from another country that have moved to the Netherlands, or because they are interested in NGT, either professionally (e.g. researchers, NGT interpreters and NGT teachers), socially (e.g. because they have a deaf colleague, friend or cousin), or because they were interested in learning a language that uses the visual-gestural modality rather than the oral-aural one.

Although little is known about the origin and history of NGT, it is assumed that it first emerged at the schools for the deaf that were established in the Netherlands between 1790 and 1888. The language's origin is the result of three factors: first, through the establishment of deaf schools, deaf people (children) who usually live in isolation because their families and the people who surround them are hearing came into contact with each other. Second, spoken language was not sufficiently accessible to the deaf pupils who attended these schools, and third, humans, hearing or deaf, have a deep desire to communicate. The deaf schools, thus, formed perfect settings for a sign language to develop, and this development took place despite the fact that the language policies of the schools have not always been supportive of the use of a signed language. In the 1980s, however, it became clear that the results of oral education (an education model in which deaf children are taught to speak, lip-read, read, and write, and where signing is discouraged or even forbidden) were poor, and linguistic research demonstrated that signed languages are real languages. Research also showed that acquisition and use of a signed language by deaf children would support rather than hamper spoken language learning and enhance a better cognitive and social-emotional development. Slowly, the use 
of signs became part of the education models used at schools for the deaf. At the start, teachers would communicate in Sign Supported Dutch (which is roughly a combination of Dutch and NGT in which Dutch sentences are spoken and NGT signs accompany content words). Since 1995, bilingual education has become available for all deaf children: a form of education in which both NGT and Dutch are used. NGT teaching materials have been developed and NGT classes are taught to the staff (and parents) in order to facilitate this type of education. The signing skills of teachers and parents vary widely, ranging from fluent NGT to use of some signs accompanying spoken Dutch.

Currently, research into NGT is conducted at two universities in the Netherlands. ${ }^{12}$ There is an education program for NGT teachers and NGT interpreters $^{13}$ and a centre of expertise on Sign Language of the Netherlands, the Dutch Sign Centre (Nederlands Gebarencentrum), was established in 1992, which also is the lexicographic institute for NGT. The Dutch government has been requested to formally recognize NGT, for several reasons but crucially so that resources would have to be provided that are necessary for a better education for the deaf (e.g. for linguistic research, development of education materials, and the right to education in NGT and to interpreting services). A prerequisite for recognition imposed by the government was standardization of NGT, since there is some amount of dialectal variation (at least in the lexicon), that originates from the different schools for the deaf. An (artificial) standardization process, coordinated by the Dutch Sign Centre had been completed in 2003, resulting in a set of 5000 basic standardized NGT signs and a basic grammar description of NGT. In spite of this, formal recognition of NGT has not taken place to date.

\section{Basiswoordenboek Nederlandse Gebarentaal (BNGT)}

With this information and that about sign language dictionary compilation in mind, let us now look at a recently published dictionary for NGT. The dictionary is the result of a joint effort by the Dutch Sign Centre (the lexicographic institute for NGT), and Van Dale, an established company specialized in the publication of dictionaries for a variety of languages. The BNGT is the latest publication in a range of printed and electronic dictionaries published by the Dutch Sign Centre, most of which are specialized in a language domain (e.g. religion, museum, topography, relations and sex) or targeted at a particular public or field (e.g. children, health services, education). There is a printed version of the BNGT and an online electronic version to which one can subscribe. Both are aimed at adult users of NGT (deaf and hearing; parents of deaf children, students of NGT, NGT teachers, and NGT interpreters).

The publication of the printed BNGT serves two main aims. First, it comprises a larger basic set of standardized NGT signs than any of the previous ones, and thus better assists the common user (and learner) of NGT. 
Second, the dictionary is to promote knowledge of the existence of NGT and understanding and acceptance of the language by the general public, as well as to raise the language's status (hopefully resulting in formal recognition of NGT by the Dutch government). The publication of the online version mainly serves to facilitate the NGT user with a dictionary that has advanced search tools and videos of the signs as well as signed example sentences. The cooperation between the Dutch Sign Centre and Van Dale has been crucial: the former bringing in expertise on NGT and sign language lexicography, the latter contributing expertise on lexicography in general and dictionary publishing, and its leading name. The official introduction of the printed BNGT (including the presentation of a copy to the Dutch minister of Education, Culture and Research) has had much media coverage, especially on television and in newspapers. Through the publication of this dictionary, many people who are not (professionally) interested in (sign) language have become aware of the existence of NGT as a real language used in the Netherlands.

\section{I First impressions of the BNGT}

4.I.I The printed version. The printed dictionary is a hard cover book and looks comprehensive, comparable to the Van Dale Basiswoordenboek Nederlands (Van Dale Basic Dictionary of Dutch, Verburg et al. 2006). It contains 560 pages, with over 3,000 standardized signs represented by line drawings in a format of six signs per page. Besides lemmas and sign pictures, it provides extra information, for example details on the articulation of the sign (manual features, including the use of space, as well as non-manual features) where these could not be sufficiently represented in a picture. For some signs, there is information about the morphological structure of the sign (viz. compound or not), and all entries provide one or more contexts in which a sign can be used; sometimes also contexts in which the sign can not be used. In a few cases, (other) Dutch translations of the sign are provided. Furthermore, the book contains information about signed languages in general and about NGT in particular in the shape of a brief overview of NGT grammar, deaf education in the Netherlands, dialect variation, and the efforts to capture the lexicon of NGT, standardization, and recognition of the language. Furthermore, it includes directions for use and an overview of the (phonetic) handshapes and mouth positions that occur in NGT signs.

Lacking sources of authentic NGT material, it was not possible to select the signs on a frequency basis. Instead, selection has been based on occurrence of signs in NGT teaching materials developed by the Dutch Sign Centre, on frequency lists of Dutch words, and on Dutch words occurring in two Van Dale dictionaries. Also, a number of signs are included that do not have a Dutch equivalent word. Although it has not been exemplified in the dictionary, 
(a)

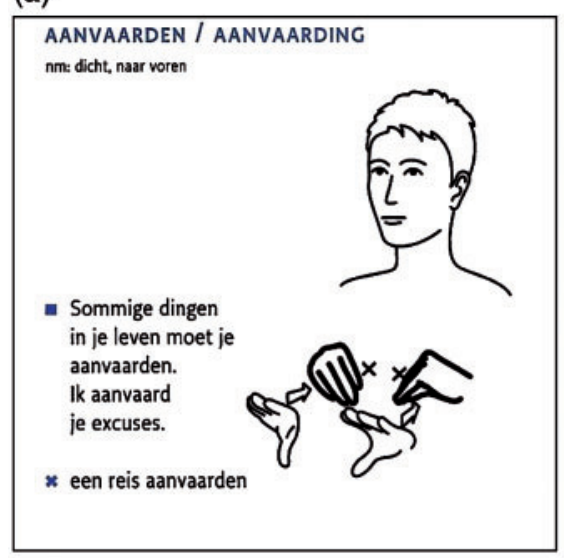

(c)

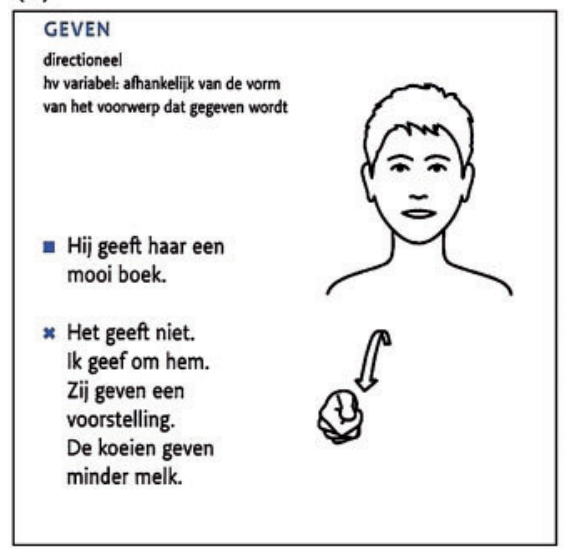

(b)

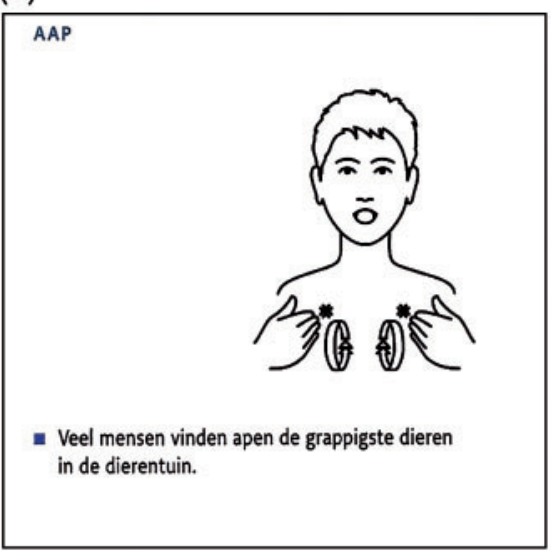

(d)

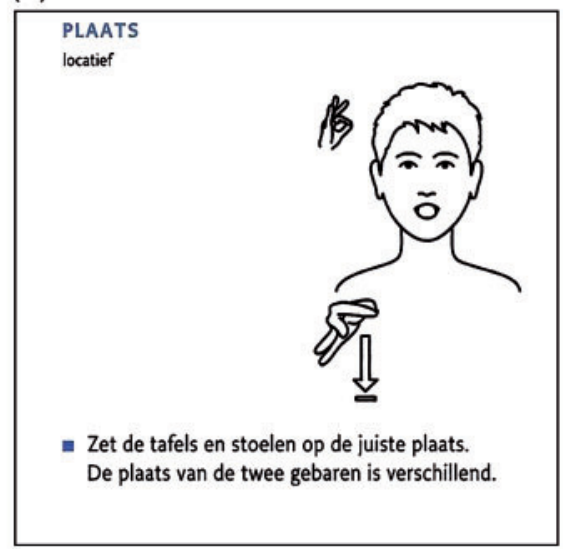

Figure 12: Four signs in the BNGT: to accept/acceptance, monkey, to give, and place.

the signs have in general been elicited. Where no single sign existed for a particular concept, a choice has been made between existing variants; in case no sign was known to exist, one was invented by a team of NGT signers (Schermer 2003).

The drawings of the signs have been made with a computer program (Sign Editor) that was especially designed for sign drawing and has been further developed through the years (Zwitserlood and Hekstra 2004). The resulting pictures are rather abstract in that they contain no unnecessary details (e.g. rings, glasses, or clothes). Besides the hand(s), a stylized head, neck and shoulders of a person are shown; these are necessary in order to mark the sign's place of articulation. Arms are only represented in the drawings of signs that are made on or near the arm. Head and face indicate non-manual components of signs, for instance a particular eye gaze, eye aperture, frown or brow raise, 
puffed cheeks, and (as far as possible) mouth activity. The activity of the hands is represented in three ways:

(i) by three-dimensional arrows, as in Figure 12;

(ii) a set of additional symbols (e.g. $\mathbf{X}$ and that indicate that the hands once or repeatedly contact body or arm, as in Figure $12 \mathrm{a}$ and $\mathrm{b}$; and

(iii) non-bold and bold printed hands (indicating the shapes and orientations of the hand at the start and end of the sign respectively, as illustrated in Figure 12a.

In signs where the hand is in such an orientation that its shape is not clearly visible, the handshape is additionally shown by a small picture in the left hand corner of the sign drawing (see Figure 12d). ${ }^{14}$

The sign-drawing program has been further refined in this particular dictionary project, ${ }^{15}$ and guidelines have been developed for a systematic method of sign representation. Still, the dictionary editors are quite aware of the fact that even systematized drawings can be unclear, and the user is recommended to also look up the signs on their website (www.gebarencentrum.nl) or in the online version of BNGT, where they are represented by movies.

In all of the examples in Figure 12, some additional information about the signs is provided in the form of one or more contexts in which the sign can be used: the Dutch sentences preceded by $\boldsymbol{~}$. In Figure $12 \mathrm{a}$ and $\mathrm{c}$ we see that sometimes also contexts are provided in which the signs can not be used (preceded by $\times$ ). Occasionally, other Dutch translations of the signs are provided; these are preceded by the + character. Many entries contain information on form or grammatical characteristics; this is given immediately below the entry. For instance, the sign in Figure 12a gives extra information on the non-manual components, indicated by $\mathrm{nm}$. The sign in Figure $12 \mathrm{~d}$ has the additional information locatief ('locative'), which indicates that it can be made at several locations in space. As for the sign for give in Figure 12c, it is mentioned that it is 'directional', which means that it can show agreement with two of its arguments (by moving from the person who is giving to the person who is receiving). It is also stated that the handshape is variable, dependent on the shape of the object that is being given.

The printed BNGT is an improvement on all previous printed NGT dictionaries: it contains more lemmas, and more information on grammatical characteristics and use of the signs than any other printed one. On the other hand, it also has a number of disadvantages, the main ones being those of all printed sign language dictionaries: insufficiently clear representation of the signs, limited search options, only a limited number of signs and no signs in signed context. The online version does not have these disadvantages. However, there are also other disadvantages, in both versions, some of which could have been avoided. These will be discussed in section 4.2 below. 


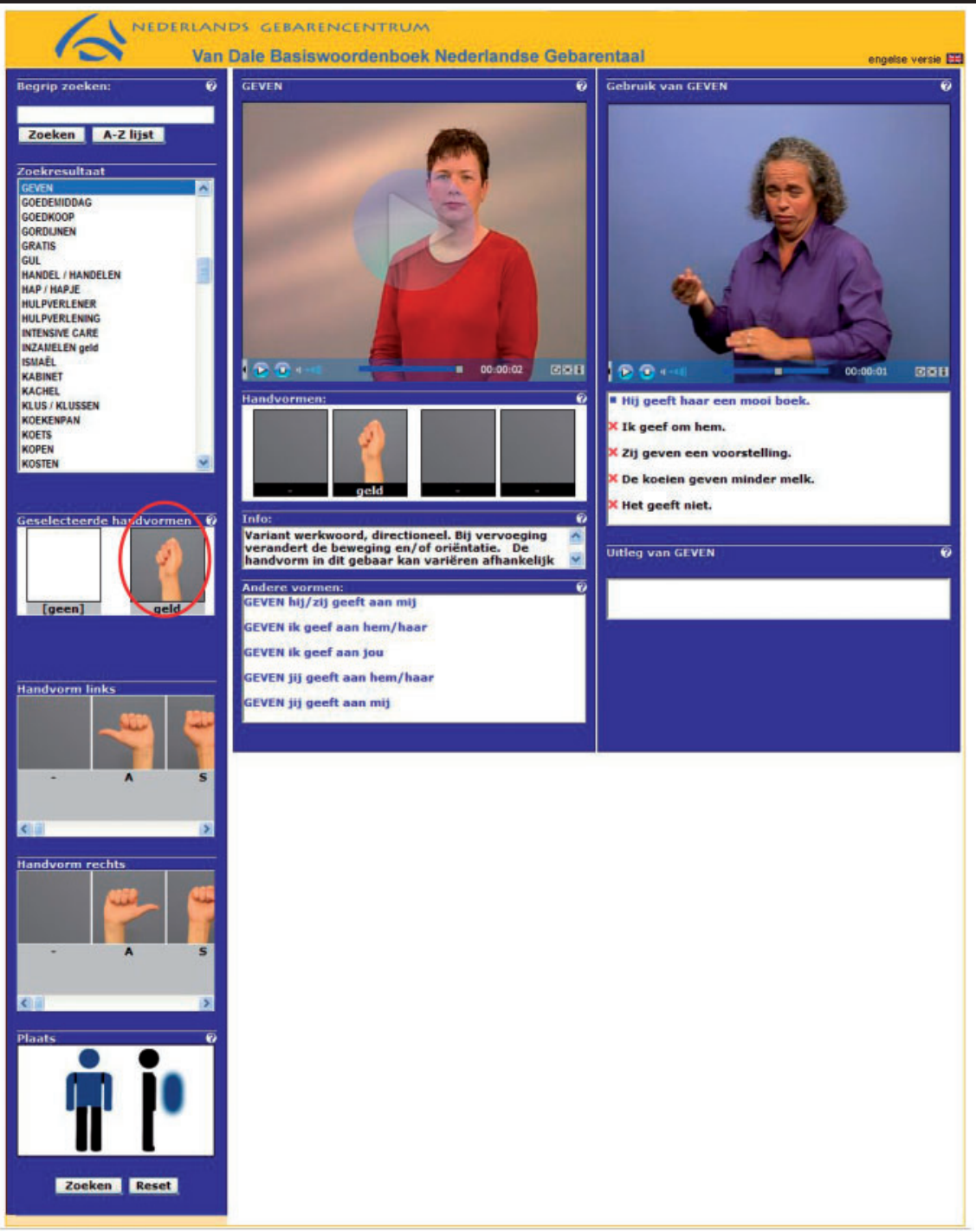

Figure 13: Sign search and representation of the NGT sign for give in the online BNGT. This figure appears in colour in the online version of the International Journal of Lexicography.

4.I.2 The online version. Publication of an online version followed shortly after that of the printed version. This version is an extension of the previous (free) online dictionary and the NGT dictionaries on DVD published by the Dutch Sign Centre. Basically, it is possible to search an NGT translation of a Dutch word as well as to search an NGT sign on the basis of a subset of its parameters, viz. on the (phonetic) shape of the hand(s) and the location of the sign. The result of a sign search is a list of Dutch words, in which each word can be 
clicked to show the movie of the corresponding sign. NGT example sentences are available for a large subset of the signs. ${ }^{16}$ Results of a search for an NGT sign based on the parameter handshape (circled), is illustrated in Figure 13. The sign for 'give' is selected from the list of hits.

The sign and the example sentence are available in video format. There is information on the form and function of the sign, slightly more extended than in the printed version, in written Dutch. Also, since the sign happens to be a directional (agreement) verb, videos of inflected forms are available. The glosses below the left video screen can be clicked to show these.

\subsection{Monolingual or bilingual?}

The title Basiswoordenboek Nederlandse Gebarentaal ('Basic Dictionary of Sign Language of the Netherlands') suggests that the dictionary is monolingual. This suggestion is supported by the editors' explicit statement that the dictionary does not have Dutch entries. Instead, the lemmas consist of glosses that represent signs. The reasoning behind this is that a sign notation system would be too opaque to the user (as sketched in section 2). However, in contrast to monolingual dictionaries all information about the lemmas is in Dutch, not in NGT (e.g. information about the word class(es) or conjugation possibilities, explanations of the meaning(s)). More importantly, the lemmas, even if they are intended to represent NGT signs, are Dutch words. Therefore, the dictionary is in fact bilingual. As a consequence, the printed version appears to be a (unidirectional) bilingual dictionary, from Dutch to NGT. The online version is also bilingual, but bidirectional. On the other hand, each lemma in a bilingual dictionary has one or more translations in the target language, viz. the different words that exist in the target language for the various meanings of the entry. But this is not the case in the dictionary under discussion, because gloss lemma and sign are considered equivalent.

It is not clear why the editors have opted for this hybrid form. It has not made their job easier, nor that of the user of the dictionary. Especially the printed version will be used as a bilingual dictionary, although it lacks certain properties. The use of gloss lemmas has led to a format with a seeming one-to-one relation between a Dutch word and an NGT sign (with the risks connected). I will return to this issue in the next section. The fact that this hybrid form has been chosen is possibly based on a strong wish to compile a (printed) unilingual dictionary while the possibilities for such a format are limited. Another possibility is that the editors wanted to avoid having to construct two dictionaries: Dutch-NGT and NGT-Dutch. Yet another option is that they wanted the format to be as similar as possible as previous versions of their electronic dictionaries, where glosses are also used. Since the choice has not been accounted for by the editors, their intention remains unclear. 
(a)

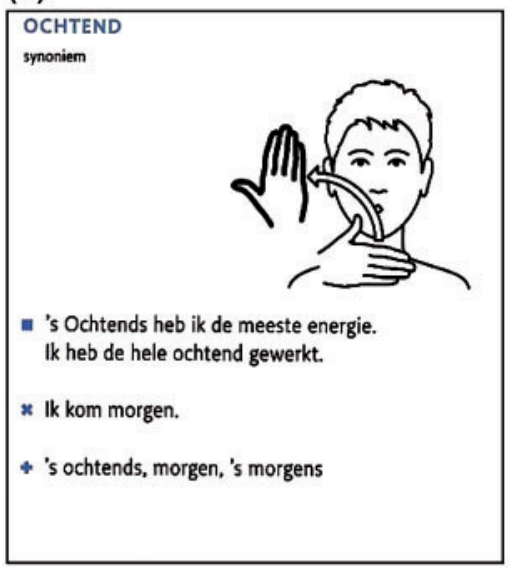

Figure 14: Representation of NGT ('morning'). This figure appears in colour in the online version of the International Journal of Lexicography.

\subsection{Gloss lemmas}

The use of gloss lemmas in the BNGT turns out to be quite confusing. As stated earlier, it seems at first sight that there is exactly one sign per Dutch word (since the glosses are Dutch words). That this is not the case can be deduced from the fact that there may be more than one entry with the same gloss, some of them with an addition. For instance, in the gloss pair OCHTEND and OCHTEND ... ('morning') we see that one of the glosses is followed by three full stops (illustrated in Figure 14a and b). The full stops indicate that the sign is an NGT synonym of the sign with the same gloss.

There are also other additions to the glosses that indicate that a Dutch word can be translated with more than one sign. In contrast to the full stops, these additions indicate the different meanings of the lemma, that each are expressed by a different sign. Some of these additions are numbers, as in LAAG1 and LAAG2 ('low' and 'level') in Figure 15a and b. Some additions contain Dutch words or phrases that give some extra information on the meaning of the gloss lemma, e.g. LAAG boven/onder ('layer'), as in Figure 15c, or on the domain in which the sign is used, for instance RECEPT dokter versus RECEPT eten ('prescription doctor' versus 'recipe food'). It is unclear why, besides words or phrases, numbers (not containing further information) are used as additions.

The use of gloss lemmas is rather awkward and would not have been necessary in a common bilingual dictionary format, where each Dutch lemma would list all the (known) NGT translations in the form of drawings or movies, or vice versa. In such a format, NGT signs would also be provided 

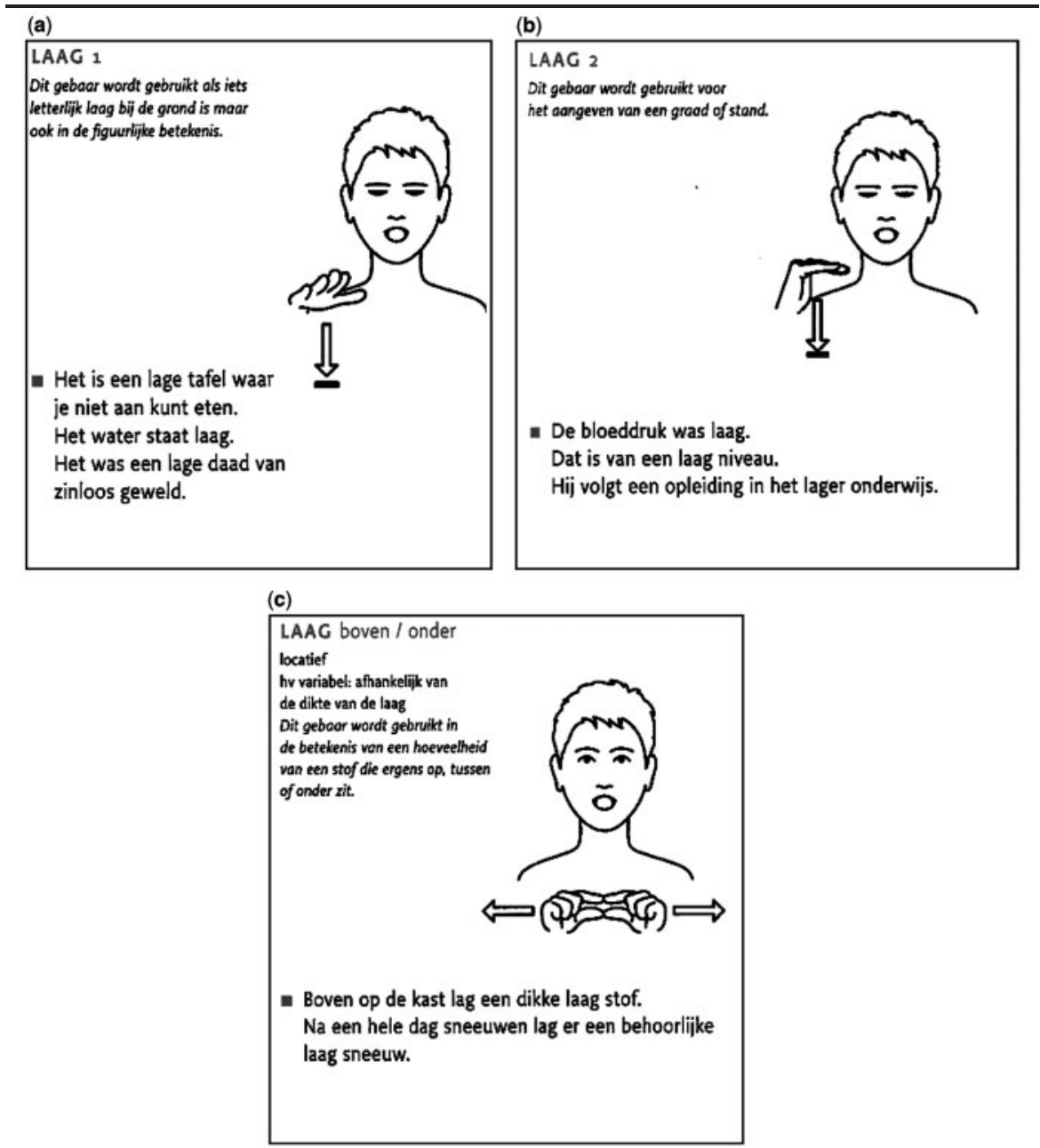

Figure 15: Representations of different NGT signs with similar glosses. This figure appears in colour in the online version of the International Journal of Lexicography.

with each Dutch word of which they are translations. For instance, the Dutch words grappig ('funny') and komisch ('comical') can be translated with the same NGT sign. In a bidirectional dictionary, the sign would be presented under both Dutch lemmas grappig and komisch, but since NGT signs are represented by a single gloss in this dictionary, there is only one gloss lemma connected with the sign: GRAPPIG, but no gloss lemma кOMISCH. It must be noted that the printed version contains a list with both gloss lemmas and Dutch words, in which the user can find the Dutch word komisch and is referred to the gloss lemma GRAPPIG. Such reference information is scant, however, and it would 


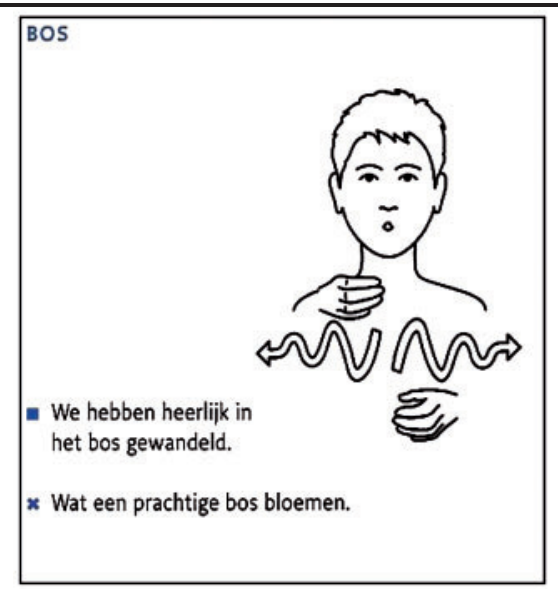

Figure 16: Gloss lemma with context and non-context sentences. This figure appears in colour in the online version of the International Journal of Lexicography.

have been much more user-friendly if this information could be found in the entries.

Finally, the BNGT contains some NGT signs for which there is no appropriate word or word combination in Dutch. Because of that, the representation of these signs as gloss lemmas is rather strange. Sometimes a whole phrase is needed, for instance MOND: MET-DE-MOND-VOL-TANDEN-STAAN ('tongue: to be completely tongue-tied'), or if this is not possible, the gloss lemma represents the mouthing that goes with the sign (e.g. in the case of an agreement auxiliary that has no counterpart in Dutch; glossed as OP).

\subsection{Explanation of the signs and example sentences}

Let us now turn to the explanation of the meaning of the signs. Most of the entries in both versions of the BNGT do not have such explanations. To some extent, the meaning is indicated by the (Dutch) gloss itself (and possible additions to it). In some cases, the meaning is clarified in the context sentences, e.g. with the gloss lemma AMBULANCE (id.): Een ander woord voor ambulance is ziekenauto ('a different word for ambulance is sick-car'), or can be deduced from these sentences. For instance, the context sentence De douane controleert de grenzen ('Customs controls the frontiers') may give some information on the sign under the gloss lemma DOUANE ('customs'). In many other cases, however, these sentences are not helpful, for instance in the case of the gloss lemma GRAS ('grass') with the context: Het gras is mooi groen ('The grass is beautifully green'). But then, as meaning retrieval was not the main aim of the sentences, this 
possibility should not be expected overall. In some cases, the meaning of the sign may be understood from its form, viz. in the case of 'iconic' signs, where the form of an object or event is (partially) reflected in the sign form. ${ }^{17}$ Only occasionally is a definition or description provided (in Dutch).

Finally, the example sentences provided with most of the entries are intended to indicate in which context or contexts the signs can be used. In the printed version of the BNGT, these sentences are in Dutch because of space limitations, but in the online version, they are in NGT. Surprisingly, there are also sentences of contexts in which the sign cannot be used. For instance, the sign in the gloss lemma Bos has the meaning of 'woods' (Figure 16). The editors provide a context sentence for this sense (We hebben heerlijk in het bos gewandeld 'We made a lovely walk in the woods'), but also a sentence for a meaning that the sign does not have, viz. the non-context sentence Wat een prachtige bos bloemen ('what a lovely bunch of flowers.'). The reason for this is that the Dutch word bos is homonymous and can be used in the sense of 'woods, forest' as well as 'bunch (of flowers)' and apparently it needs stressing that this does not hold for the NGT sign. Again, in a normal bilingual format, this would not have been necessary, and it would be explained elsewhere (e.g. under the lemma bloem 'flower') how one would express the concept of a bunch of flowers.

Information on the provenance of examples sentences used in the dictionary is not provided, and it is quite possible that these sentences are not authentic, but have been invented for the purpose. As is common for such examples in many dictionaries, not all of them are natural; some are even rather odd, for instance Slapen op een boot is een bijzondere ervaring ('Sleeping on a boat is an exceptional experience') with the gloss lemma воот ('boat'). The need for invented sentences may be reduced in the future when various NGT sources are used.

Summarizing, if the BNGT is, indeed, intended as a monolingual NGT dictionary, the explanation of the signs is very scant, and it assumes that the user has a fundamental knowledge of Dutch. Instead of providing the user with explanations of the meaning of signs, the dictionary often leaves the users to extract this information themselves from various parts within and outside of the entry. This, as well as the use of non-context examples suggests (again) that the BNGT is basically a bilingual Dutch-NGT dictionary; the printed version being unidirectional and the online version being, to some extent, bidirectional.

\subsection{Grammar: overview and grammatical information per lemma}

The printed version of the BNGT provides a (sixteen page) overview of the basic characteristics of the grammar of NGT. This can be helpful for the starting NGT learner and for the generally interested user, to get an idea of 
the structure of NGT. The grammar and especially the articulation of a visual-gestural language are quite different from what most (hearing) people are used to. Therefore, the form characteristics of signs are explained extensively. Besides phonetics, also sign formation, syntactic issues, and the lexicon are discussed. The ordering could have been clearer if headings and subheadings for the various topics had been used. The terminology might have been better tuned to the average Dutch person, who is not familiar with (sign language) linguistic terms such as object, SOV, modal verbs, classifier, frozen and productive lexicon. This can be remedied in a next edition.

Research on NGT does not have a long tradition and much of the grammar is still unknown or has been studied superficially so far, although there are also detailed studies of isolated grammatical phenomena. It is quite striking that some of the research findings from the past decade are not present or not fully correctly represented. This holds especially for research into phonology and phonetics, but also for morphology and syntax. It must be admitted, though, that it is not easy to translate research findings into clear information for a naive language user or learner. On the other hand, some of the grammatical phenomena that are discussed do not seem to be based on any research or are based on insufficient research. For instance, the use of the term 'compound' for particular sign combinations suggests a particular morphological structure, whereas it is unclear so far whether the sequential sign combinations termed as such are indeed complex signs or rather phrases, or else perhaps literal translations from Dutch compounds rather than NGT compounds.

The information on NGT grammar contains examples for illustrative purposes, which are almost all in glosses, and therefore not very informative. This holds especially for the gloss examples in the subsections describing the form of signs. For example, it is stated on page $26^{\text {' }} \mathrm{Er}$ zijn klopbewegingen uit de pols (NA), knokkels van de vingers (SCHILDEREN fijn) en vingergewrichten (SCHIETEN)' ('There are movements from the wrist [AFTER], finger joints [TO PAINT art] and finger joints [то Sноот]'). Unless the dictionary users make the effort of looking up the signs, the information that they get from this description is that the sign glossed as NA apparently has a movement from the wrist rather than that the movement itself is illustrated by an image of the movement. As for the glossed examples of sentences, these are not illustrative either unless one is used to reading gloss examples and familiar with the signs that are represented. The example in (1) illustrates this. It is taken from page 37 where the use of an NGT auxiliary glossed as op is exemplified:

(1) Hij is al weken verliefd, niet op haar maar op jou!

$$
\begin{aligned}
& \text { - }{ }^{-}{ }^{-} \\
& \text {('HEKEN TIJD has been in love for weeks already, not with her but } \\
& \text { with you!' }
\end{aligned}
$$




\section{_neg_ \\ WEEKS TIME until INDEX he IN.LOVE heON $_{\text {she }}($ heONyou $)$}

In addition to the grammar overview, many of the lemmas in the dictionary include grammatical information. Most of this information is clear when the user has carefully read and understood the grammar overview or has received NGT instruction. However, it may also be somewhat opaque. For instance, it is not indicated to which body part the information on the non-manual component or components (nm) exactly refers in the lemma AANVAARDEN/ AANVAARDING ('accept/acceptance') (Figure 12a; the information is repeated and translated in (2)). It is probably the mouth that should be or become closed, but it is unclear whether it is the head or the body (or both) that should be in a forward position or move forwards.

(2) nm: dicht, naar voren (nm: closed, forwards)

Three aspects are missing in the grammatical information in the entries. First, in spite of the statement in the grammar overview that NGT signs belong to particular word classes, the word class of signs is not indicated. Some gloss lemmas consists of both a noun and a verb, e.g. AANVAARDEN/AANVAARDING ('accept/acceptance') in Figure 12a. The user is apparently expected to deduce the word class from the Dutch gloss, because the Dutch word usually belongs to a particular word class (or to more than one). As has been stated earlier, however, the word class of the Dutch word does not necessarily match that of the NGT sign and the user may draw the wrong conclusion. This is apparent in the case of the gloss lemma RIJ mensen ('LINE people'), where the user may deduce that the sign is a (monomorphemic) noun, whereas it actually is a (complex) predicate). In addition, some sign combinations are claimed to consist of a sign and a classifier, for example the sign under the gloss lemma RIJBEWIJS ('driver's license'), that is analysed as a compound of the sign glossed as Auto ('car') and a classifier. The word class of such constructions is not clear at all.

Second, as stated in the previous section, some lemmas contain sentences of contexts in which the sign can not be used. Unfortunately, in the majority of cases it is not indicated which sign or construction should be used instead in these contexts, which is a serious lack of information, especially because it cannot be found elsewhere. Third and related to the previous point, the shape of the hand is apparently variable in some signs (e.g. in the sign for give, Figure 12c, where it is claimed to be dependent on the object being given). A user who needs to express the concept of giving for a particular object will often not be able to find the correct shape, however. In some cases where information on different handshapes is provided, this is done under different gloss lemmas. For instance, different handshapes are given in 


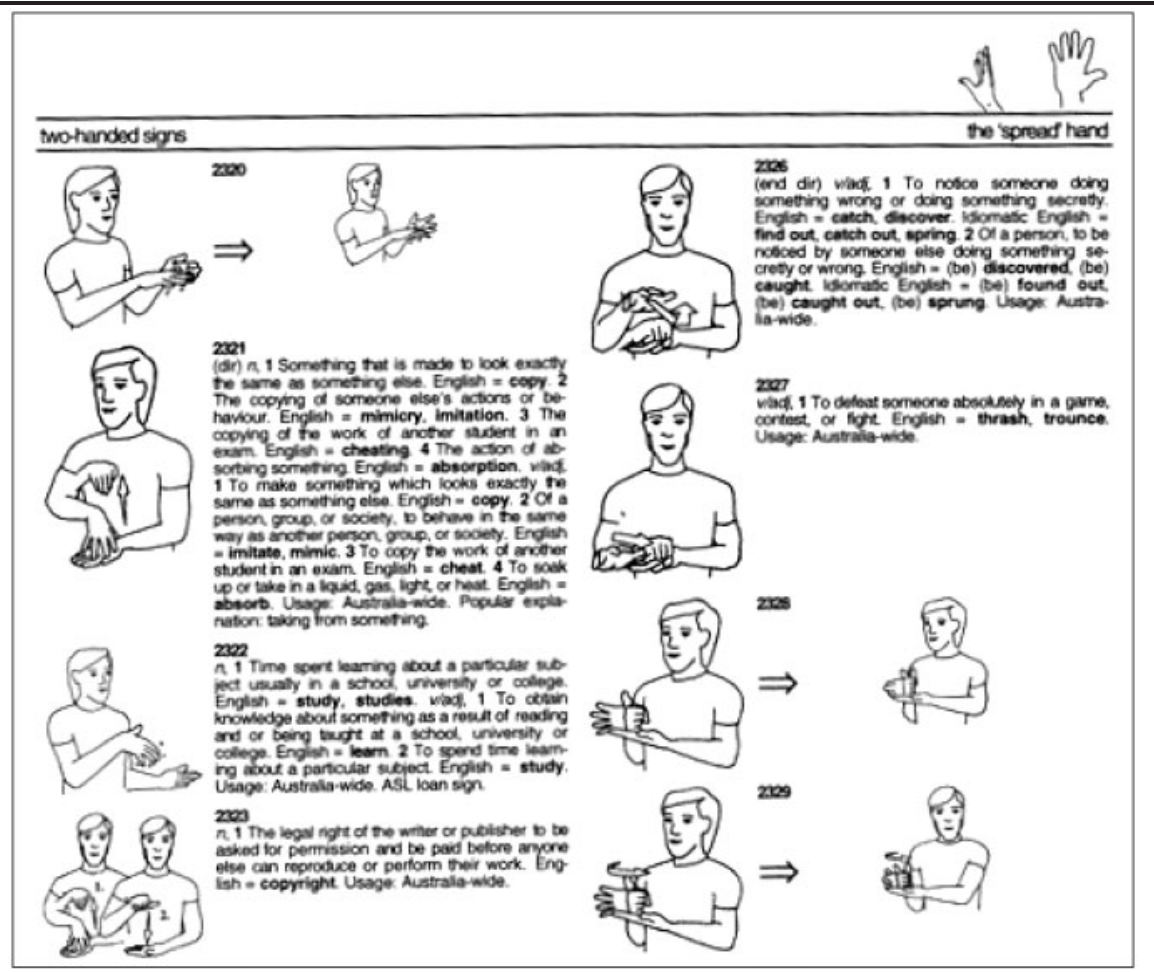

Figure 17: Example (part of) page from the Auslan dictionary (Johnston 1998: 263. Copyright (C) 1998; reprinted with kind permission of the author.)

the gloss lemmas LEGGEN platte voorwerpen, LEGGEN stapel, and LEGGEN sleutels; 'PUT flat objects (somewhere)', 'PUT stack (somewhere)', and 'PUT keys (somewhere)'. The users are left to search the information in other entries.

\subsection{Design and comparison with other dictionaries}

4.6.I The printed BNGT. As we can conclude from the previous sections, the design of the printed BNGT with representation of signs by combinations of gloss lemmas and sign pictures is not very felicitous. The use of gloss lemmas is confusing and the gloss-sign picture combination may even, unintentionally, lead the dictionary user to the false idea that each Dutch word has a (single) NGT equivalent.

The strict gloss-sign picture combination in the printed version considerably restricts the number of entries: it contains merely 3,000 lemmas. This is extremely few compared to spoken language dictionaries, such as the monolingual Van Dale Basiswoordenboek Nederlands ('Basic Dictionary of Dutch'), which has 50,000 entries, and the Van Dale Pocketwoordenboek NederlandsFrans ('Pocket dictionary Dutch-French'), with a basic vocabulary of French of 
over 30,000 entries. Naturally, the limited number of entries is partly due to the fact that the sign pictures require much space. On the other hand, the space needed could have been reduced considerably if the dictionary had been unidirectional Dutch-NGT, if the gloss-picture combination had been less strict, and if the available space had been used more efficiently. Not only do many of the entries contain quite a bit of white space (e.g. Figure 12a, b, and d), but also all information about synonymous signs is unnecessarily repeated (e.g. Figure $14 \mathrm{a}$ and $\mathrm{b}$ ). An example of a sign language dictionary with more efficient use of space is the bilingual, unidirectional printed Auslan dictionary (Johnston 1998), which contains almost the double number of sign pictures $(5,500)$ as well as much more information on the meaning, use and grammatical characteristics of the signs than the BNGT (as can be seen in Figure 17).

Even though the printed version of the BNGT is an improvement to all previously printed NGT dictionaries, the chosen hybrid form and design have quite a few unnecessary disadvantages that should be remedied in new editions.

4.6.2 The online version of the BNGT. The online version of BNGT is in many respects preferable over the printed version. Although it currently contains rather few signs (3000, just like the printed version), this set will soon be extended to at least 7000 signs, including all the signs from the various existing electronic DVD dictionaries with jargon from various fields (e.g. museum, health service). Storage on the internet is virtually unlimited and many more signs than 7000 can and have to be included. Although a computer is needed (instead of simply taking a book from the shelf), this has the advantage, on the other hand, that access to the dictionary is possible from every location where an internet connection is available. The representation of signs by movies is by far more accurate than that by sign pictures and the inclusion of NGT example sentences a large improvement.

Nevertheless, the current format leaves a few things to be desired. The circuitous access to the dictionary, the fast time-out, the necessity to precisely double-click on a lemma in order to see the sign movie can hopefully be quite easily fixed. The most important adaptation, however, would be that towards a bidirectional bilingual design in which Dutch and NGT entries are used instead of gloss lemmas, and all (known) translations of the lemmas are listed. Moreover, instead of listing signs as Dutch words (glosses), stills of the signs should be listed, preferably ordered on the basis of sign parameters.

The sign search options need extending and refinement, and could do with a more user-friendly interface (especially since the web site does not fit the computer screen and one has to scroll down to access the sign parameter search options). Options for movement search should be provided in addition to the search options by handshape and location. The options for searching on place of articulation could be extended to finer-grained locations on the body 
and in space (alongside with the current, global ones). The handshape search option should be extended with a possibility to search on global shapes (e.g. a general category 'flat hand' alongside the current four phonetic variants) and be more easily accessible (currently one needs to scroll through a long list of shapes). It must be noted that the use of photos of handshapes is an improvement for the layman or beginning signer to the use of handshape names (e.g. 'B0', 'As', or 'baby snavel' ('baby beak')) in previous electronic NGT dictionaries. Another option would be to make searches possible for signs with a change in the handshape (e.g. when the hand goes from closed to open or vice versa). The formats of the recently published online dictionaries of SSL, DTS and SVK can be taken as a model. In addition it would be useful to have the possibility of downloading sign drawings (that is available for a subset of the signs in the most recent DVD NGT dictionaries) or movie stills, especially for those who work with children acquiring NGT and those who teach NGT or learn NGT as a second language. Finally, wherever possible, signs, their meanings, and example sentences should come from natural sources, in order to provide the user with the most reliable information.

\section{Conclusion}

Summarizing it can be said that, although the printed BNTG is an improvement on all previous printed NGT dictionaries, it still has quite a number of shortcomings. Some of these are unavoidable, and due to the specific problems of sign language lexicography, such as the lack of an easy notation for signs and the lack of sources. Other shortcomings, however, could have been avoided. The choice to use gloss lemmas and the fact that the basis of the dictionary is Dutch (instead of NGT) in particular have hampered the compilation of a mature dictionary, like the Auslan and BSL dictionaries. The BNGT apparently still suffers from old traditions in the construction of sign language dictionaries, and the extensive experience in dictionary publishing of Van Dale is surprisingly absent in the BNGT. In spite of all good intentions and hard work on the side of the editors, the user of the dictionary faces the task of extracting information (on meaning and grammatical characteristics) about the signs from the glosses (plus additions), from other glosses, from (Dutch) example sentences, from the grammar overview and from the word list. Instead, this information should have been provided in a clear way in the entries. As dictionary users may not be able to do this or not be willing to make the effort (not many dictionary users read introductions and instructions carefully), there is a risk that the dictionary gives rise to wrong ideas or conclusions about NGT (signs). The choice for a design with a strict ordering of six gloss lemmas and sign pictures per page has led to inefficient use of space and limited the number of entries to 3,000, whereas inclusion of the full set of 5,000 standardized signs and corresponding information would have been possible in a still manageable 
book. The online version, although it has more and better search options and good representations of the signs and example sentences, still shares many of the weaknesses of the printed version and can also be considerably improved.

As stated earlier, the printed version of the BNGT was constructed with two aims: to assist NGT users, and to promote knowledge about, as well as acceptance, and ultimately recognition, of NGT. It appears to have given a boost to the general Dutch public towards acknowledgement of an as yet rather unknown language that is used in the Netherlands, and to have stimulated popular recognition of NGT being a real language, especially since the well-known Van Dale Company was involved in the publication of the dictionary. So far, the second aim seems to be met. As for the first aim, we must conclude that the BNGT still has many drawbacks. Neither the Deaf user nor the NGT learner is facilitated by a dictionary in which a sign cannot be looked up in order to find its Dutch translation. And especially learners of NGT need much more than a dictionary with only a very small set of signs and little information (some of which is hidden), even if the book itself can be easily taken off the shelf for quick consultation. NGT users are much better served with the online version, especially when the number of entries will be extended and adaptations will have been made according to the above suggestions.

\section{Acknowledgements}

This paper has much benefitted from comments on earlier versions by Adam Schembri, Ernst Thoutenhooft and an anonymous reviewer. Jette Hedegaard Kristoffersen and Thomas Troelsgård have been very helpful with information about the DTS dictionaries, and Tommi Jantunen with information about the SVK online dictionary. I acknowledge with thanks their contributions; all (remaining) inaccuracies are my responsibility.

\section{Notes}

1 The term deaf is commonly used to refer to a physical disability, whereas Deaf (with capital) indicates: belonging to a community that shares Deaf culture and a signed language.

2 This is also the case for the majority of spoken languages, but for those among them for which dictionaries are compiled, orthographies are developed.

3 This does not hold for languages whose writing system is not generally based on sounds, viz. Chinese.

4 See Miller (2001) for a general overview of sign notation systems.

5 http://www.viittomat.net/.

$6 \mathrm{http}: / /$ www.tegnsprog.dk/.

7 A gloss in the context of signed languages should be seen as a label (written in capitals) for a sign, that gives (one of) the sign's meaning(s) in a spoken language. Often, glosses are words from the spoken language that is used in the same country as the signed language. For instance, the gloss HOUSE represents a sign from a signed language 
(e.g. BSL or ASL) for the sign for the concept that in English is expressed by the word house.

8 http://aslbrowser.commtechlab.msu.edu/browser.htm.

9 It must be noted that such movies may not provide too reliable sources since the (status of the) language is not always clear and highly variable.

10 Compare examples (i) from Hebrew (Aronoff et al. 2005: 316) and (ii) American Sign Language (Lillo-Martin 1991). In (ii) $t$ indicates topicality and $b r$ raised eyebrows. The line of these markers over the signs a ${ }_{a}$ JULIE and from ${ }_{b}$ STEVE to PAPER indicates the scope over which these markers are used. The subscripts ${ }_{\mathrm{a}}$ en ${ }_{\mathrm{b}}$ indicate points in space to which Julie and Steve are assigned and which are used with the verb for 'give' to mark subject and object agreement (Steve is the subject, Julie the object) and with the pronoun to indicate its referent.

(i) ha- 'even

DEF.ART- stone.FEM.SG roll.past -FEM.SG

'the stone rolled'

(ii) $\frac{\mathrm{t}}{{ }_{a} \mathrm{JULIE}} \frac{\mathrm{br}}{{ }_{b} \mathrm{STEVE}_{b} \mathrm{GIVE}_{a}\left({ }_{a} \mathrm{PRONOUN}\right) \text { PAPER}}$, NOT-IMPORTANT

As for Julie, that Steve gives (her) the paper is not important.

11 Other possible glosses would be MAKE-UP Or WARRIOR, in case they would be elicited by these English words or occur in contexts in which such interpretations were feasible.

12 These are the University of Amsterdam and the Radboud University in Nijmegen.

13 These education programs are provided by the Institute for Signs, Language and Deaf Studies (IGT\&D) at the Hogeschool Utrecht.

14 All illustrated citations from the BNGT are under copyright of the Dutch Sign Centre, and reprinted here with their permission.

15 Still, the program has limitations and candidate signs for the dictionary that could not be clearly drawn have been excluded.

16 The set of example sentences is currently being extended to example sentences for all signs, and the present set of 3,000 standardized signs will be expanded in the near future.

17 'Iconicity' in language, especially in signed languages, is a controversial issue. Let it suffice here to say that signs are only 'iconic' if the observer knows the object or event well enough to understand the aspect that is reflected in the form of the sign, and, often also only if the meaning of the sign is known already. Thus, the combination of the Dutch gloss and the form of the sign may be helpful to understand the sign's meaning.

\section{References}

\section{A. Dictionaries}

Brien, D. (ed.) 1992. Dictionary of British Sign Language/English. London: Faber and Faber.

Boerrichter, C. P. M. 2009. Van Dale Pocketwoordenboek Nederlands-Frans (Van Dale Pocket Dictionary Dutch-French) (Fourth edition). Utrecht and Antwerpen: Van Dale Lexicografie.

Center for Tegnsprog. 2008. Ordbog over Dansk Tegnsprog. (The Danish Sign Language Dictionary.) http://www.tegnsprog.dk/. 
Costello, E. 1998. Random House Webster's American Sign Language Dictionary. New York: Gallaudet University Press.

DAC (Deaf Action Committee for Sign Writing. 2010. http://www.signbank.org/ SignPuddle1.5.

Institutionen för Lingvistik. 2009. Svenskt teckenspråkslexikon 2009. http:// 130.237.171.78/fmi/iwp/cgi?-db= Digital\%20version \%20av\%20Svenskt\%20 teckenspr\% $\%$ C3\% A kslexikon\&-loadframes.

Jørgensen, Johannes (ed.) 1907. De døvstummes Haandalfabet og 280 af de almindeligste Tegn (The hand alphabet of the deaf-mutes and 280 of the most common signs). Copenhagen: Alfred Jacobsen.

Johnston, T. 1989. Auslan Dictionary: a Dictionary of Australian Sign Language (Auslan). Adelaide: TAFE National Centre for Research and Development.

Kuurojen Liittory. 2003. Suvi Suomalaisen viittomakielen verkosanakirja. http://www .viittomat.net/.

Stokoe, W. C., D. C. Casterline and C. G. Croneberg. 1965. A Dictionary of American Sign Language on Linguistic Principles. Washington, DC: Gallaudet College Press.

Van Herreweeghe, M., S. Slembrouck and M. Vermeerbergen. 2004. Digitaal Vlaamse Gebarentaal-Nederlands/Nederlands-Vlaamse Gebarentaal woordenboek. http:// gebaren.ugent.be/.

Verburg, M., E. van Rijsewijk and L. Permentier. 2006. Van Dale Basiswoordenboek Nederlands (Van Dale Basic Dictionary of Dutch). (Third edition). Utrecht and Antwerpen: Van Dale Lexicografie.

Vicars, W. 1997-2009. ASL dictionary. http://www.lifeprint.com/dictionary.htm.

\section{B. Other literature}

Aronoff, M., I. Meir and W. Sandler. 2005. 'The Paradox of Sign Language Morphology.' Language 81-2, 301-344.

Brien, D. and M. Brennan. 1995. 'Sign Language Dictionaries: Issues and Developments.' In H. Bos and G. Schermer (eds), Sign Language Research 1994: Proceedings of the Fourth European Congress on Sign Language Research, Munich, September 1-3, 1994. International Studies on Sign Language and Communication of the Deaf 29. Hamburg, Signum Verlag, 313-338.

Brien, D. and G. Turner. 1994. 'Lemmas, Dilemmas and Lexicographical Anisomorphism: Presenting Meanings in the First BSL-English Dictionary'. In I. Ahlgren, B. Bergman and M. Brennan (eds), Perspectives on Sign Language Usage: Papers from the Fifth International Symposium on Sign Language Research, 2. Durham: The International Sign Linguistics Association (ISLA), 391-407.

Crasborn, O. and I. Zwitserlood. 2008. 'The Corpus NGT: an Online Corpus for Professionals and Laymen'. In O. Crasborn, T. Hanke, E. Efthimiou, I. Zwitserlood and E. Thoutenhoofd (eds), Construction and Exploitation of Sign Language Corpora. 3rd Workshop on the Representation and Processing of Sign Languages. Paris: ELDA, 44-49.

Johnston, T. 1987. Preliminary Signing Dictionary of Australian Sign Language. Adelaide: TAFE National Centre for Research and Development.

Johnston, T. 2003. 'Language Standardization and Signed Language Dictionaries.' Sign Language Studies. 4-3, 431-468.

Johnston, T. 2009. 'Creating a Corpus of Auslan within an Australian National Corpus'. In K. Burridge, M. Haugh, J. Mulder and P. Peters (eds), HSCNet Workshop Proceedings: Designing the Australian National Corpus, UNSW, Sydney, 4-5 December 2008. Sydney: HSCNet. 
Johnston, T. and A. Schembri. 1999. 'On Defining Lexeme in a Sign Language.' Sign Language and Linguistics. 2.1, 115-185.

Lillo-Martin, D. 1991. Universal Grammar and American Sign Language: Setting the Null Argument Parameters. Dordrecht: Kluwer Academic Publishers.

Meir, I., W. Sandler, C. Padden and M. Aronoff (in press). 'Emerging Sign Languages.' . In M. Marschark and P. Spencer (eds), Oxford Handbook of Deaf Studies, Language, and Education, 2.

Miller, C. 2001. 'Some Reflections on the Need of a Common Sign Notation System.' Sign Language and Linguistics. 4.1-2, 11-28.

Prillwitz, S., R. Leven, H. Zienert, T. Hanke and J. Henning. 1989. HamNoSys version 2.0. Hamburg notation system for sign languages: an introductory guide. Hamburg: Signum.

Schermer, G. M. 2003. 'From Variant to Standard: An Overview of the Standardization Process of the Lexicon of Sign Language of the Netherlands over Two Decades.' Sign Language Studies. 3.4, 469-486.

Slobin, D. I. 2008. 'Breaking the Molds: Signed Languages and the Nature of Human Language.' Sign Language Studies. 8.2, 114-130.

Stokoe, W. C. 1960. Sign Language Structure. An Outline of the Visual Communication Systems of the American Deaf. Silver Spring, MD: Linstok Press.

Tervoort, B. T. 1953. Structurele analyze van visueel taalgebruik binnen een groep dove kinderen. (Structural Analysis of Visual Language Use in a Group of Deaf Children.) Amsterdam: Noord-Hollandsche Uitgevers Maatschappij.

Zwitserlood, I. and D. Hekstra. 2004. 'Sign Printing System - SignPS.'. In O. Streiter and C. Vettori (eds), Proceedings of the LREC 2004 Satellite Workshop on Representation and processing of sign languages, 82-84

Appendix: List of signed languages mentioned in this paper

Signed languages are usually indicated by abbreviations of their names that can be in English or in the local spoken language. The names combine the country in which the language is used as the fact that it is a signed language. The signed languages mentioned in this paper are summarized below.

ASL

Auslan

BSL

DTS

NGT Nederlandse Gebarentaal

SSL

SVK Suomalaisen Viittomakielen

VGT Vlaamse Gebarentaal
American Sign Language

Australian Sign Language

British Sign Language

Danish Sign Language

Sign Language of the Netherlands

Swedish Sign Language

Finnish Sign Language

Flemish Sign Language 